\title{
RESPONSABILIDADE PENAL E NOVAS TECNOLOGIAS: DESAFIO DO DIREITO NO SÉCULO XXI SOBRE O USO DE DRONES OU VANT' $S^{*}$
}

\section{PENAL RESPONSIBILITY AND NEW TECHNOLOGIES: CHALLENGE OF THE LAW IN THE 21ST CENTURY ON THE USE OF DRONES OR VANT'S}

\author{
Priscila Elise Alves Vasconcelos** \\ Cleyson de Moraes Mello***
}

\begin{abstract}
Resumo: $O$ presente trabalho tem por objetivo demonstrar como o ordenamento jurídico brasileiro vem tratando de questões envolvendo novas tecnologias. Dentre as inovações surgidas nos últimos tempos, foi delimitado o escopo da pesquisa nos drones ou veículos aéreos não tripuláveis, os VANT's. Com o advento da regulamentação da ANAC em 2017, algumas lacunas foram preenchidas e outras permaneceram. $\mathrm{O}$ objetivo central da pesquisa é demonstrar como a regulamentação da agência federal trata dos drones no aspecto penal e se o tratamento definido se enquadra às demandas atuais. Para isso foi realizado um estudo bibliográfico e empírico, com base em dados oficiais, legislação pertinente e jurisprudência. Foi realizada uma análise inicial com os principais países da Europa e o tratamento penal atribuído para os incidentes envolvendo a tecnologia aqui discutida.
\end{abstract}

Palavras-chave: Responsabilidade Penal. Drones. Legislação.

Abstract: This paper aims to demonstrate how the Brazilian legal system comes dealing with issues involving new technologies. One of the innovations that have emerged in recent times, was delimited the scope of the search in the drones or unmanned aerial vehicles, the UAV ' $\mathrm{s}$. With the advent of the regulations of ANAC in 2017, some gaps were filled and other remained. The main objective of the research is to demonstrate how the federal agency about the drones in the criminal aspect and treatment set fits to current demands. For this we conducted a bibliographical and empirical study, based on official data, relevant legislation and case law. An innicial analysis was conducted with the main countries of Europe and the penal treatment assigned to the incidents involving the technology discussed here.

Keywords: Criminal Liability. Drones. Legislation.

\footnotetext{
* Uma versão modificada deste artigo foi publicada no livro "Estudos em Homenagem ao Professor Doutor José Rogério Moura de Almeida Filho", de coordenação de Cleyson de Moraes Mello, José Rogério Moura de Almeida Neto e Regina Pentagna Pentrillo.

** Doutoranda em Direito pela Universidade Veiga de Almeida (RJ), Mestra em Agronegócios pela Universidade Federal da Grande Dourados (MS), Especialista em Meio Ambiente pela COPPE UFRJ (RJ), Especialista em Direito Público e Direito Privado pela EMERJ ESA (RJ). Pesquisadora nas áreas de Direito Ambiental e Direito de Energia. Advogada. Bolsista PROSUP/ CAPES/UVA.

*** Professor Adjunto da Faculdade de Direito da UERJ. Departamento de Teorias e Fundamento do Direito. Diretor Adjunto da Faculdade de Direito de Valença - RJ; Professor Titular da Universidade Estácio de Sá - Rio de Janeiro - Brasil; Doutor e Mestre em Direito. profcleysonmello@hotmail.com.
} 


\section{INTRODUÇÃO}

O presente trabalho tem por intuito verificar como a ciência do Direito vem enfrentando as questões das novas tecnologias. As inovações tecnológicas surgem a cada instante no mundo e nem sempre os regulamentos e legislações se encontram em conformidade, sendo um verdadeiro desafio.

O aspecto jurídico das inovações tecnológicas, muitas vezes, são confundidas apenas com a rede internacional de computadores, relacionado aos crimes digitais. Ocorre que a temática é muito mais ampla e aborda a inteligência artificial, uma das grandes novidades do século XXI.

Com base nessa premissa desafiadora, deu-se início ao estudo acerca dos drones ou VANT's, veículos aéreos não tripuláveis. Os antigos aeromodelos da década de 80 passam a ter nova roupagem e nova tecnologia, sendo utilizados nas mais diversas áreas: militar, segurança, jornalística, recreativa dentre outros.

Dentro da temática inteligência artificial, encontram-se os drones ou vant's. Isso ocorre pelo nível tecnológico aplicado a esses objetos, independentemente da atividade-fim que venham a exercer: militar ou recreativa.

Mediante tais fatos, perfaz-se necessário que a ciência jurídica se adeque às atuais necessidades. No caso específico, é preciso que o direito penal tutele de forma adequada os eventuais ilícitos que venham a ocorrer.

Todavia, para que se apure de forma adequada as infrações pertinentes, é necessário realizar um estudo sobre a competência legislativa bem como sobre a atuação das agências reguladoras. Isso é imprescindível a fim de verificar qual a sanção penal a ser aplicada e qual o órgão competente para julgar e processar.

A preocupação com relação a aplicabilidade de normas de caráter penal ocorre muito pela facilidade de acesso e uso dos atuais aeromodelos no âmbito recreativo. Comumente utilizados em filmagens de casamentos, fotos de paisagens, transmissão de campeonatos, em muitos casos os drones se encontram sobre as cabeças da população sem qualquer tipo de fiscalização ou cautela.

Em busca de respostas plausíveis ao ordenamento jurídico brasileiro, foi realizado um estudo bibliográfico, com base em artigos científicos, dados oficiais, 
regulamentos aplicados e de jurisprudência, objetivando levantar as informações necessárias à pesquisa.

Por fim, é abordado de forma breve como o uso de drones ou vant's recreativos estão sendo tratados na Europa. Apresenta-se um apanhado de notícias de 2017 e 2018 sobre a temática e auxiliar no entendimento da conclusão sobre o estágio da regulação brasileira. Em trabalho futuro, será realizado o estudo comparativo com outros países.

\section{DA COMPETÊNCIA LEGISLATIVA}

$\mathrm{Na}$ análise de uma temática, é preciso uma verificação prévia do contexto constitucional acerca da competência para legislar. Sendo a Constituição da República Federativa do Brasil uma constituição analítica (SLAIBI FILHO, 2003) e econômica (CANOTILHO, 1993), o seu texto evita qualquer discricionariedade pelo legislador e possui preceitos que garantem a organização e funcionamento da economia.

A República Federativa do Brasil é composta pela união indissolúvel dos seguintes entes: Estados, Municípios e o Distrito Federal ${ }^{1}$ (BRASIL, 1988). Por se tratar de uma constituição analítica, encontra-se em seu texto a descrição das competências dos entes federativos. No artigo 21 da Carta (BRASIL, 1988), o constituinte originário elencou as competências de cada ente, podendo ser privativa, reservada, concorrente ou suplementar.

Para Silva (2015), ao abordar a temática competência, trata-se da faculdade atribuída juridicamente a uma entidade, órgão ou agente do Poder Público para a emissão de decisões. A Constituição da República (BRASIL, 1988) adotou o princípio da prevalência do interesse como forma de designar a competência dos entes federados. Nesse sentido, cabe a União legislar sobre matérias de interesse geral, aos Estados e Distrito Federal as matérias de interesse regional e, por fim, aos Municípios e ao Distrito Federal aquelas cujo interesse local seja preponderante.

O artigo 21 da Constituição Federal cuida da competência exclusiva da União, enquanto que o artigo 22 trata da sua competência privativa para legislar.

\footnotetext{
${ }^{1}$ Art. 10. Da Constituição da República Federativa do Brasil (BRASIL, 1988). 
Importante destacar que no parágrafo único do artigo 22 , há a previsão de lei complementar autorizativa de matérias remanescentes, devidamente especificadas no texto constitucional (BRASIL, 1988).

Já o artigo 23 da Carta (BRASIL, 1988), traz as competências distribuídas entre os entes da federação, sendo as comuns. Cita-se a proteção ao meio ambiente como uma competência comum a todos os entes federativos.

O artigo 24 da Constituição da República (BRASIL, 1988) trata da competência concorrente, ou seja, matérias que competem à União, Estados e Distrito Federal. Caberá a União estabelecer normas gerais enquanto que aos Estados e Distrito Federal aquelas normas específicas. Importante destacar que o parágrafo $3^{\circ}$ do artigo 24 é claro ao dispor que na ausência de lei federal sobre normas gerais, os Estados exercerão a plenitude de competência, visando atender suas peculiaridades. Trata-se de uma competência suplementar descrita na própria Constituição Federal, onde no caso de superveniência de lei federal sobre a norma geral, ocorre a suspensão da eficácia da norma estadual geral.

Conforme o artigo 21, inciso XII, alínea c da Constituição da República (BRASIL, 1988), caberá a União a exploração da navegação aérea, podendo fazê-lo de forma direta ou mediante autorização, concessão ou permissão.

O objeto de estudo é a normatização para trafegar veículos aéreos não tripulados, os VANT'S, que circulam no espaço aéreo brasileiro. Mediante isso, é preciso verificar de quem será a competência para legislar e regulamentar o seu uso.

Após a verificação acerca da competência sobre os drones ou vant's, é preciso analisar a responsabilidade penal no caso de ilícitos ocorridos através dos equipamentos.

No tocante ao aspecto penal, é preciso verificar o disposto no artigo 22, inciso I da Carta de 1988. É competência privativa da União legislar sobre direito penal. Nesse caso, é necessário adequar a legislação acerca do uso de drones ou vant's com as normas constitucionais acerca da responsabilidade penal.

Com o advento da Agência Nacional de Aviação Civil2 em 2005, a União Federal exerce a sua competência descrita no art. 21, inciso XII, alínea c da Constituição da República. Através da agência reguladora de âmbito nacional, a

2 Lei 11.182/2005. Cria a Agencia Nacional de Aviação Civil Brasil (2005). 
União regula e fiscaliza as atividades de aviação civil e de infra-estrutura aeronáutica e aeroportuária (BRASIL, 2005).

Outrossim, verifica-se que se trata de matéria de competência da União Federal, que a exerce através de sua agência reguladora desde 2006, ao tratar de aeromodelos não recreativos.

Com relação aos recreativos e de acordo com o exposto, a competência legislativa será a municipal, tendo por fundamento o art. 30, I da Carta de $1988^{3}$.

\section{DA REGULAMENTAÇÃO DA ANAC}

De acordo com a ANAC (AGENCIA NACIONAL DE AVIAÇÃO CIVIL, 2017a), a expressão drone pode ser utilizada para descrever qualquer aeronave ou outro veículo que possua elevado grau de automotismo. A ANAC não utiliza essa nomenclatura e sim aeromodelos ou aeronaves remotamente pilotadas - RPA, sendo a diferença entre elas a finalidade que possuem. Os aeromodelos são utilizados para fins recreativos, enquanto as aeronaves remotamente pilotadas possuem qualquer outra finalidade não recreativa, seja corporativa ou não.

O dia 03 de maio de 2017 foi o marco regulatório acerca do uso de drones. A Agência Nacional da Aviação Civil editou o Regulamento Brasileiro da Aviação Civil Espacial - RBAC-E (AGENCIA NACIONAL DE AVIAÇÃO CIVIL, 2017b), elencando as exigências para o uso de aeronaves não tripuladas. De acordo com a norma, deverão ser observadas as regulamentações de outros entes da Administração Pública, como a Agencia Nacional de Telecomunicações (ANATEL), o Departamento de Controle do Espaço Aéreo - DECEA e o Ministério da Defesa.

O Regulamento Brasileiro de Aviação Civil Especial - RBAC -E no 94 (AGENCIA NACIONAL DE AVIAÇÃO CIVIL, 2017b), editado através da Resolução 410/2017 da ANAC, tem por escopo a viabilidade das operações com elevado nível de segurança. De acordo com a agência, as regras instituídas também têm por objetivo a promoção do desenvolvimento sustentável e seguro ao setor (AGENCIA NACIONAL DE AVIAÇÃO CIVIL, 2017a).

\footnotetext{
${ }^{3}$ Art. 30. Compete aos Municípios: I - legislar sobre assuntos de interesse local;(...). Constituição da República (BRASIL, 1988).
} 
Conforme a ANAC, além do Regulamento RBAC-E no. 94, outras normas precisam ser observadas. As instruções suplementares IS no. E94-001, IS no. E94002 e IS no. E 94.503-001 (AGENCIA NACIONAL DE AVIAÇÃO CIVIL, 2016) são algumas normas técnicas de procedimentos específicos que devem ser seguidos.

Tendo em vista a existência de elevado nível de complexidade e risco nas operações e equipamentos, os limites definidos na legislação tiveram por base regulamentações de autoridades de aviação civil de outros países, como a Federal Aviation Administration - FAA - dos Estados Unidos, Civil Aviation Safety Authority CASA - da Austrália, e, por fim, European Aviation Safety Agency - EASA - da União Europeia.

Importante destacar que a partir de 03 de maio de 2017, qualquer aeronave não tripulada seja de uso recreativo, corporativo, comercial ou experimental, deverá se enquadrar nas regras definidas pela ANAC. Ressalta-se que há outras normas complementares como as da ANATEL - Agencia Nacional de Telecomunicações, DECEA - Departamento de Controle de Espaço Aéreo e o Ministério da Defesa.

Existem algumas premissas para a regulamentação do uso de drones (AGENCIA NACIONAL DE AVIAÇÃO CIVIL, 2017a). Dentre eles, pode-se destacar a viabilização de operações (comerciais), desde que a segurança às pessoas permaneça preservada, minimização de ônus administrativo e burocracia, e a permissão de evolução conforme o setor se desenvolve.

Imprescindível destacar que a própria resolução dispõe de forma expressa a não possibilidade de drones em centros urbanos, salvo situações peculiares como no caso de segurança pública. É preciso um distanciamento de 30 metros da população local por questão de segurança individual. Essa proibição não ocorre em áreas agrícolas, geralmente não ou pouco habitáveis.

Ressalta-se ainda o uso da tecnologia para controle sanitário e ambiental, sendo cabível uma isenção específica definida na IS E94-002. Mesmo entendimento para o uso pelo Corpo de Bombeiros dos estados, onde o risco pelo não uso em determinado salvamento ou situação de perigo pode ocasionar um dano muito maior. 


\section{DA RESPONSABILIDADE PENAL}

Até o presente momento, o trabalho trouxe a análise das regras aplicáveis ao uso de drones ou vant's recreativos. Foi abordado também as questões de competência legislativa de acordo com as regras estabelecidas na Constituição da República (BRASIL, 1988).

Acerca da responsabilização pela prática de ilícitos de natureza penal, o Regulamento da ANAC, o Regulamento Brasileiro da Aviação Civil Especial - RBAC-E n. 94, dispõe em seu item E-94.701 a possibilidade de aplicação do Decreto-Lei 3.688 de 1941 (BRASIL, 1941). Trata-se da lei de contravenções penais e da previsão expressa do artigo $33^{4}$.

Segundo Freitas (2017), não há uma tipificação penal específica com relação ao uso irregular de drones. Cita o autor que é possível aplicar o art. 261 do Código Penal (BRASIL, 1984) nos eventos ocorridos junto aos aeroportos, como no caso de Congonhas ${ }^{5}$ em 12 de novembro de 2017.

Conforme a regra do artigo 261 do Código Penal, é cabível a aplicação de pena de reclusão para aqueles que expõe a perigo aeronave ou praticam qualquer ato capaz de impedir ou dificultar o tráfego aéreo. E foi efetivamente o que ocorreu em São Paulo, onde por duas horas o aeroporto de Congonhas permaneceu fechado, ocasionando um verdadeiro caos.

Para Freitas (2017), essa tipificação não pode ser aplicada no caso de jogos esportivos ou em outros incidentes ocorridos com drones ${ }^{6}$. Complementa informando que a aplicação do artigo 33 da Lei das Contravenções Penais para aqueles que não possuírem licença para pilotagem é uma sanção meramente simbólica, não tendo um caráter repressivo.

É importante verificar que não há um tipo penal específico sobre os possíveis crimes causados pelo uso inadequado de drones. Têm-se, por exemplo, o uso do

\footnotetext{
${ }^{4}$ Art. 33. Dirigir aeronave sem estar devidamente licenciado: Pena - prisão simples, de quinze dias a três meses, e multa, de duzentos mil réis a dois contos de réis (BRASIL, 1941).

${ }^{5}$ Drone fecha Congonhas por $2 \mathrm{~h}$, afeta voos e complica rotina de passageiros. Matéria de Rodrigo Borges Delfim (2017).

${ }^{6}$ Drone invade arena do Corinthians. É ilegal em estádios e tem riscos. Reportagem de Daniel Lisboa (2015).
} 
equipamento para ingressar junto à penitenciárias, como ocorreu em Dourados ${ }^{7}$, Mato Grosso do Sul, e em Ipaba8, Minas Gerais. Ambos os eventos ocorreram em 2018, após o advento da regulamentação pela Agência.

O Ministério Público do Estado de Rio Grande do Sul denunciou sete pessoas por um fato ocorrido em novembro de 2016. Durante um jogo ocorrido no final de campeonato, um drone contendo uma faixa provocativa sobrevoou o estádio Beira Rio. Após a partida, um grupo de torcedores depredou uma residência acreditando que o equipamento não estaria mais no local, o que não era verdade. Dos sete torcedores, dois foram denunciados por incitação à violência e manuseio não autorizado de aeronave, enquanto os demais foram denunciados pela prática de ato de violência em ambiente esportivo, dano qualificado e violação a domicílio9 ${ }^{\text {. }}$

Em março de 2017, o Ministério Público do Estado de Mato Grosso denunciou dois membros de uma das maiores organizações criminosas do Brasil, o Comando Vermelho. A denúncia ocorreu por utilizarem drones contendo aparelhos telefônicos - celulares - que entraram na Penitenciária Central do Estado.

Importante, também, abordar eventos ocorridos em outros países da América Latina a fim de ilustrar possíveis ilícitos penais envolvendo o uso dos veículos aéreos não tripuláveis.

Em 2015, durante a realização de um show na Plaza de Toros de Playa em Tijuana, México, o cantor Enrique Iglesias sofreu um grave acidente ao perceber que um drone se encaminhava em sua direção. O artista, no âmbito de se proteger do "ataque", ergueu os braços para pegar o objeto. Sofreu diversas feridas causadas pelas hélices do veículo aéreo ${ }^{10}$.

Se esse fato ocorrido com o Enrique Iglesias tivesse sido no Brasil, não haveria uma tipificação clara para adequar o fato a conduta. O tipo penal mais próximo seria o artigo 129 do Código Penal (BRASIL, 2018), que cuida do crime de lesões corporais, mas é preciso verificar qual o dolo do agente. Ademais, destaca-se

\footnotetext{
${ }^{7}$ Polícia abate drone que sobrevoava penitenciária em Dourados, MS (TV MORENA, 2018).

${ }^{8}$ Drone usado para levar droga e celular para penitenciária de Ipaba é abatido a tiro (DIÁRIO DO AÇO, 2018).

9 Ministério Público denuncia sete pessoas em caso de drone que sobrevoou Beira-Rio (SABALLA JR., 2017).

${ }^{10}$ Enrique Iglesias Suffers Bloody Injury in Drone Accident at Tijuana, Mexico Concert (HELLER, 2015).
} 
que no direito penal não é cabível aplicar a analogia in malam partem, o que poderia trazer a sensação de impunidade em alguns casos.

Imprescindível discutir a temática tendo em vista que não há tipos penais específicos na regulamentação hoje vigente.

\subsection{Da responsabilidade penal das pessoas jurídicas}

De acordo com pesquisadores da School of Engineering e Edith Cowan University, dos Estados Unidos, até 2016, um percentual superior a 64\% dos acidentes ocorridos com drones ou vant's estão diretamente relacionados a falhas técnicas (HANDRAN, 2016).

Segundo os pesquisadores, as falhas encontradas estão na comunicação entre os drones e seus joystick - controles remoto. Para Graham Wild, um dos responsáveis pela pesquisa, é necessário uma legislação mais rígida além da melhora dos sistemas tecnológicos aplicados ao equipamento.

A temática envolvendo a responsabilidade penal da pessoa jurídica é de extrema importância, principalmente pelo fato do ordenamento jurídico brasileiro apresentar essa previsão na lei de crimes ambientais (BRASIL, 1998).

Para tanto, a regulamentação existente deve abordar de forma mais rígida eventuais ilícitos penais e não apenas os de natureza administrativa e cível.

\section{DA REGULAMENTAÇÃO PELA COMUNIDADE EUROPEIA E REPERCUSSÕES}

Questões envolvendo o uso de drones ou vant's na Europa precisam ser analisados de forma a verificar se a regulamentação aplicada no Brasil está condizente ou não com a tendência mundial.

Além da regulamentação já descrita no trabalho, no Brasil também é necessário o registro junto a Agencia Nacional de Telecomunicações - ANATEL, a fim de evitar interferências em outros aparelhos que necessitam de comunicações via satélite.

Algumas questões peculiares sobre a segurança no uso de drones já atingiu o Brasil e outros países já desenvolvidos e com regulamentação mais consolidada. 
Em alguns países europeus como Bélgica e Suécia já houve uma maior restrição ao uso ou até mesmo o banimento para aqueles amadores.

Segundo Botija (2018), as forças de segurança da Europa consideram os drones como uma real ameaça à segurança e não apenas um risco potencial. Para o autor, os riscos - de acordo com a Agência Europeia para segurança da aviação EASA - podem ser detalhados como a capacidade de gerar acidentes e incidentes tanto no chão como no ar.

Botija (2018) aduz que, de forma efetiva, o usuário dos VANT's ou drones podem de forma involuntária causar danos e até mesmo agir contra a segurança coletiva.

Em junho de 2017, Portugal já apresentava um regulamento para o uso de drones, mas não possuía capacidade fiscalizatória. Por ser integrante da União Europeia, é signatário da legislação comum que prevê o registro de propriedade e identificação eletrônica do aparelho. Ocorre que àquela época não estava ainda vigente, encontrando-se em fase de consulta pública. A preocupação portuguesa ocorria pelos sucessivos incidentes com drones e a ausência de regras claras que dispusessem sobre responsabilização e controle dos equipamentos (FERRO; LIMA, 2017).

Na Espanha, com a edição do Real Decreto 1036/2017, foi analisado o uso de drones e a relação com a segurança pública. De acordo com Botija (2018), o decreto foi dedicado de forma precisa à segurança, prevendo regras para que a execução de operações necessite de comunicação prévia ao Ministério do Interior no prazo mínimo de dez dias da operação. A medida visa a restrição ou proibição de operações que podem ensejar riscos à proteção de pessoas ou até mesmo danos patrimoniais.

Incidentes ocorridos na Rússia também fizeram o governo local reavaliar o uso de drones em seus territórios, pleiteando uma regulamentação mais severa na Europa (SPUTNIK NEWS, 2018).

Em abril de 2018, foi publicada a informação em sítio eletrônico que a Agência Europeia de Segurança da Aviação - EASA - está para publicar uma legislação que proíbe o uso de drones recreativos sem licença nos países que fazem 
parte da comunidade europeia. Outros países que não integram a União Europeia como a Suíça tendem a adotar a mesma legislação (KESTELOO, 2018).

Em meados de 2018, Portugal, através da sua agência de aviação civil, reportou 16 incidentes ocorridos pelo uso de drones apenas no primeiro semestre. Em 2017 foram instaurados 15 processos contraordenacionais. Os eventos ocorridos em 2018 estão relacionados à utilização indevida nas proximidades de aeroportos.

De acordo com a legislação portuguesa, o Decreto-Lei 58/2018, vigente desde julho, tornou obrigatório o registro dos aparelhos que possuam mais de 250 gramas, além da necessidade de seguros de responsabilidade civil para aqueles aparelhos com mais de 900 gramas. Uma vez violada alguma regra, é possível a aplicação de multa de 300 a 7.500 euros, além da apreensão temporária dos equipamentos. Interessante que as penalidades aqui elencadas são de natureza civil $^{11}$.

Portanto, constata-se que tanto no Brasil quanto em diversos países europeus há uma preocupação quanto à regulamentação do uso dos VANT's ou drones para evitar os abusos de fato e de direito que podem ocasionar instabilidade social e danos morais e materiais.

\section{CONCLUSÃO}

Através do estudo realizado, foi possível verificar que a atual regulamentação acerca do uso de drones ou vant's apresenta uma lacuna no tocante a responsabilização penal.

Como pode ser verificado tanto na regulamentação brasileira, através da ANAC, como nas existentes na Comunidade Europeia, ainda há muitas lacunas a serem solucionadas. Problemas pela ausência de uma regulamentação mais rígida estão levando países a proibir o uso dos equipamentos da modalidade recreativa.

No caso do Brasil, apesar de constar uma previsão de aplicabilidade do Decreto-lei 3.688/41, lei de contravenções penais, foi possível verificar através de casos concretos trazidos que é necessário uma melhor adequação do fato à norma. É

${ }^{11}$ Aviação reportou 16 incidentes com 'drones' no primeiro semestre do ano (CORREIO DA MANHÃ, 2018). 
preciso lembrar que os aparelhos possuem hélices (geralmente entre quatro e seis) que uma vez em contato com o corpo humano podem causar lesões corporais de todos os níveis.

De acordo com o verificado junto à regulamentação da ANAC, há uma preocupação maior na apuração de responsabilidade de natureza cível e administrativa. $\mathrm{O}$ aspecto penal se limita a ausência de licença ou certificação sendo previsto a aplicação da contravenção penal descrita no artigo 33 do decreto-lei.

É urgente e necessário que o Direito se adeque às inovações tecnológicas com a aplicação de princípios basilares como da legalidade, previsto no artigo 10. Do Código Penal. Ademais, na ausência de tipos penais específicos não será possível aplicar a analogia uma vez que é proibida quando in malam partem.

Deve o Poder Legislativo, através de suas atribuições, verificar as lacunas existentes e preenche-las através de elaboração de legislações atualizadas. É a forma que o Direito tem de se adequar às inovações e garantir a efetividade da aplicação das normas.

Em futuro trabalho será abordado as questões ambientais e penais, tendo em vista a possibilidade de impacto negativo que o uso de drones ou vant's pode causar ao meio ambiente natural.

\section{REFERÊNCIAS}

AGENCIA NACIONAL DE AVIAÇÃO CIVIL. Legislação. Instruções Suplementares. ANAC, 10 mar. 2016. Disponível em: http://www.anac.gov.br/assuntos/legislacao/legislacao-1/iac-e-is/is. Acesso em: 29 maio 2018.

. Regulamento Brasileiro de Aviação Civil Especial: RBAC-E no 94. Requisitos gerais para aeronaves não tripuladas de uso civil. [Brasíli, DF]:ANAC, 2017b. Disponível em: http://www.anac.gov.br/assuntos/legislacao/legislacao1/rbha-e-rbac/rbac/rbac-e-94-emd-00/@@displayfile/arquivo_norma/RBACE94EMD00.pdf. Acesso em: 20 maio 2018.

. Regras da ANAC para uso de drones entram em vigor. Brasília, DF: ANAC, 2017a. Disponível em: http://www.anac.gov.br/noticias/2017/regras-da-anacpara-uso-de-drones-entram-em-vigor/release_drones_v2.pdf. Acesso em: 20 mai 2018.

BOTIJA, Fernando G. Drones: seguridad pública y régimen sancionador. Revista Vasca de Administración Pública.Herri-Arduralaritzako Euskal Aldizkaria, 
[Logroño], n. 111, p. 271-310, maio/ago. 2018. Disponível em:

https://www.euskadi.net/r61-

s20001x/es/t59aWar/t59aMostrarFicheroServlet?t59aIdRevista=2\&R01HNoPortal=tru e\&t59aTipoEjemplar $=$ R\&t59aSeccion $=41 \&$ t59aContenido $=2 \&$ t59aCorrelativo $=1 \& t 59 a$ Version=1\&t59aNumEjemplar=111. Acesso em: 01 out 2018.

BRASIL. [Constituição (1988)]. Constituição da República Federativa do Brasil de 1988. Brasília, DF: Presidência da República, [2016]. Disponível em: http://www.planalto.gov.br/ccivil_03/Constituicao/Constituiçao.htm. Acesso em: 10 maio 2018.

. Decreto-lei no 3.688, de 3 de outubro de 1941. Lei de Contravenções Penais. Rio de Janeiro: Presidência da República, 1941.Disponível em: http://www.planalto.gov.br/ccivil_03/decreto-lei/Del3688.htm. Acesso em: 10 jun. 2018.

. Lei no 7.209, de 11 de julho de 1984. Altera dispositivos do Decreto-Lei no 2.848, de 7 de dezembro de 1940 - Código Penal, e dá outras providências. Brasília, DF: Presidência da República, 1984. Disponível em: http://www.planalto.gov.br/ccivil_03/LEIS/1980-1988/L7209.htm\#art1_. Acesso em: 07 jun. 2018.

. Lei no 11.182, de 27 de setembro de 2005. Cria a Agência Nacional de Aviação Civil - ANAC, e dá outras providências. Brasília, DF: Presidência da República, 2005. Disponível em: http://www.planalto.gov.br/ccivil_03/_ato20042006/2005/lei/l11182.htm. Acesso em: 30 maio 2018.

. Lei no 13.715, de 24 de setembro de 2018. Altera o Decreto-Lei $n^{0}$ 2.848, de 7 de dezembro de 1940 (Código Penal), a Lei no 8.069, de 13 de julho de 1990 (Estatuto da Criança e do Adolescente), e a Lei no 10.406, de 10 de janeiro de 2002 (Código Civil), para dispor sobre hipóteses de perda do poder familiar pelo autor de determinados crimes contra outrem igualmente titular do mesmo poder familiar ou contra filho, filha ou outro descendente. Brasília, DF: Presidência da República, 2005. Disponível em: http://www.planalto.gov.br/ccivil_03/_Ato20152018/2018/Lei/L13715.htm. Acesso em: 10 jun. 2018.

CANOTILHO, José Joaquim Gomes. Direito Constitucional. 6. ed. Coimbra: Almedina. 1993.

CORREIO DA MANHÃ. Aviação reportou 16 incidentes com 'drones' no primeiro semestre do ano. [S.I.], 5 ago. 2018).

https://www.cmjornal.pt/portugal/detalhe/20180805_1040_aviacao-reportou-16incidentes-com-drones-no-primeiro-semestre-do-ano. Acesso em 04 dez 2018.

DELFIM, Rodrigo Borges. Drone fecha Congonhas por $2 \mathrm{~h}$, afeta voos e complica rotina de passageiros. Folha de São Paulo, Congonhas, 13 nov. 2017. Disponível em: https://www1.folha.uol.com.br/cotidiano/2017/11/1934992-drone-fecha- 
congonhas-por-2h-afeta-voos-e-complica-passageiros.shtml. Acesso em 04 dez. 2018.

DIÁRIO DO AÇO. Drone usado para levar droga e celular para penitenciária de Ipaba é abatido a tiro. Ipaba, 29 jul. 2018. Disponível em:

https://www.diariodoaco.com.br/ler_noticia.php?id=60971\&t=drone-usado-paralevar-droga-e-celular-para-a-penitenciaria-de-ipaba-e-abatido-a-tiro. Acesso em: 04 dez. 2018.

FERRO, Carlos; LIMA, Carlos Rodrigues. Lei mais rígida sobre uso de drones marca passo na agência europeia. Diário de Notícias. [S.I.], 19 jun. 2019. Disponível em: https://www.dn.pt/sociedade/interior/lei-mais-rigida-sobre-uso-de-drones-marcapasso-na-agencia-europeia-8573022.html. Acesso em: 29 mai 2018.

KESTELOO, Haye. Hobby drone pilots in the EU and Switzerland will soon need a license. DroneDJ. [S.I.], 19 abr. 2018. Disponível em:

https://dronedj.com/2018/04/19/hobby-drone-pilots-in-the-eu-and-switzerland-willsoon-need-license/. Acesso em: 29 maio 2018.

HANDRAN, Louise. Tech issues cause most drone accidents: Research. EurekAlert. Washington, 23 ago. 2016. Disponível em:

https://www.eurekalert.org/pub_releases/2016-08/ru-tic082216.php. Acesso em: 03 dez. 2018.

HELLER, Corine. Enrique Iglesias Suffers Bloody Injury in Drone Accident at Tijuana, Mexico Concert: See the Scary Photos. ENEWS. Cidade do México, 1 jun. 2015. Disponível em: https://www.eonline.com/news/661646/enrique-iglesias-suffersbloody-injury-in-drone-accident-at-tijuana-mexico-concert-see-the-scary-photos. Acesso em: 04 dez. 2018.

FREITAS, Vladimir Passos. A regulamentação do uso de drones, o passado e o futuro. Conjur, Segunda Leitura, [S.I.], 10 dez. 2017. Disponível em: https://www.conjur.com.br/2017-dez-10/regulamentacao-uso-drones-passadofuturo. Acesso em 29 maio 2018.

LISBOA, Daniel. Drone invade arena do Corinthians. É ilegal em estádios e tem riscos. UOL, São Paulo, 20 maio 2015. Disponível em:

https://esporte.uol.com.br/futebol/ultimas-noticias/2015/05/20/drone.htm. Acesso em 04 dez 2018.

SILVA, José Afonso da. Curso de Direito Constitucional Positivo. 38. ed. rev. São Paulo: Malheiros, 2015.

SLAIBI FILHO, Nagib. Direito Constitucional. Rio de Janeiro: Forense, 2004.

SPUTNIK NEWS. Rússia quer regulamentação mais severa sobre drones na

Europa. [Rússia], 16 fev. 2018. Disponível em: 
https://br.sputniknews.com/russia/2018021610546728-russia-dronesregulamentacao/. Acesso em 29 maio 2018.

TV MORENA. Polícia abate drone que sobrevoava penitenciária em Dourados, MS. G1, dourados, 14 jan. 2018. Disponível em: https://g1.globo.com/ms/mato-grossodo-sul/noticia/policia-abate-drone-que-sobrevoava-penitenciaria-em-douradosms.ghtml Acesso em 04 dez 2018.

SABALLA JR., Leo. Ministério Público denuncia sete pessoas em caso de drone que sobrevoou Beira-Rio. RBS TV. G1, Porto Alegre, 22 ago. 2017. Disponível em:

https://g1.globo.com/rs/rio-grande-do-sul/noticia/ministerio-publico-denuncia-setepessoas-em-caso-de-drone-que-sobrevoou-beira-rio.ghtml. Acesso em: 04 dez. 2018. 